\title{
Microalgal-immobilized Biocomposite Scaffold Fabricated by Fused Deposition Modeling 3D Printing Technology for Dyes Removal
}

Xinshu Xia ${ }^{1}$, Xiaorong Xu${ }^{1}$, Chensheng Lin $^{2}$, Yujin Yang ${ }^{1}$, Lingxing Zeng ${ }^{1}$, Yinglian Zheng ${ }^{1}$, Xinru $\mathrm{Wu}^{1}$, Wei Li ${ }^{1}$, Liren Xiao Qingrong Qian $^{1^{*}}$ and Qinghua Chen ${ }^{1 *}$

Here, the biosorption process for the removal of methylene blue (MB) was developed using three-dimensional printed biocomposite scaffolds obtained from Polylactide / Poly(butylene adipate-coterephthalate) (PLA/PBAT)-immobilized biomass of Chlorella pyrenoidosa (PIBCP). The adsorption capacity of the 3D printed PIBCP was carried out. And the effects of adsorbent dose, initial dye concentration, solution $\mathrm{pH}$, ionic strength, temperature, and contact time on the adsorption performances were discussed. The results show that the decolorization rate for methylene blue on the 3D printed PIBCP30 (with $30 \%$ mass of Chlorella pyrenoidosa) is $92.66 \%$ at the adsorption time of $24 \mathrm{~h}$. The material also shows a good recyclability to have $72 \%$ of removal efficiency after six cycles. Kinetic and adsorption isotherm models indicate that the adsorption of methylene blue onto the 3D printed PIBCP30 occurs mainly through chemisorption. Langmuir maximum adsorption capability of methylene blue on the 3D printed PIBCP30 is calculated to be of $35.21 \mathrm{mg} / \mathrm{g}$ (100 mg/ $\mathrm{g}, 298.15 \mathrm{~K})$. The adsorption is determined to be endothermic and spontaneous. The results indicate that Polylactide/Poly (butylene adipate-coterephthalate) (PLA/PBAT)-immobilized biomass of Chlorella pyrenoidosa (PIBCP) is a promising material for dye removal and the $3 \mathrm{D}$ printing technique can be employed to fabricate adsorbent for large-scale wastewater treatment.

Keywords: Biosorption; Biocomposite; Chlorella pyrenoidosa; Methylene blue; Fused deposition modeling

Received 29 November 2019, Accepted 15 February 2020

DOI: $10.30919 / \mathrm{esmm} 5 \mathrm{f} 706$

\section{Introduction}

Contamination with dyes is a major problem because a large proportion of dyes are toxic to human life and the environment. Various processing techniques, including aerobic or anaerobic digestion, coagulation, advanced oxidation processes, and adsorption, have been developed to treat wastewater, and these methods vary in effectiveness, economic cost, and environmental impact. ${ }^{1}$

The adsorption process has been proved to be superior to other methods owing to its high efficiency, flexibility, ease of operation, insensitivity towards toxic pollutants, economic feasibility. ${ }^{2}$ During adsorption, the dye is transferred from the aqueous solution to the solid phase, markedly decreasing dye content in aqueous effluent. ${ }^{3-5}$ Various adsorbents, such as agricultural wastes, chemically modified lignin, ${ }^{5}$ chitosan, algae, Kyllinga brevifolia lignin, ${ }^{5}$ biochar, ${ }^{6}$ cellulose, ${ }^{7,8}$ and fungal biomass, ${ }^{6,9}$ have been developed to remove dyes from aqueous solutions.

Several studies have suggested that microalgae are ideal biosorbents for wastewater treatment systems because their biomass contains a lot of special functional groups, such as carboxyl, sulfate, hydroxyl, phosphate, and other charged groups, which can provide active sites for pollutant binding. ${ }^{10-12}$ However, microalgal biosorbents are difficult to harvest, dewater, and reuse, because of free microalgal cells dispersed throughout the wastewater, ${ }^{13,14}$ thereby limiting the potential value of this method in large-scale applications. Microalgae immobilization techniques may be an alternative approach to

\footnotetext{
${ }^{I}$ Engineering Research Center of Polymer Green Recycling of Ministry of Education, Fujian Normal University, Fuzhou 350007, China ${ }^{2}$ College of Life and Science, Fujian Normal University, Fuzhou 350117, China

*E-mail: cqhuar@fjnu.edu.cn (Q.Chen); qrqian@fjnu.edu.cn (Q. Qian)
} 
overcome this limitation. ${ }^{15}$ For example, polyethyleniminebased sorbents have been developed for immobilization and harvesting of microalgal cells. ${ }^{16}$ Microalgae immobilized by an electrospun polysulfone nanofibrous web have also been developed for removal of reactive dyes. ${ }^{14}$ However, these immobilized microalgae techniques have several limitations, such as poor mechanical properties of the material, high cost, environmentally damaging composition, fixed shape and size, and difficulty with practical real-life applications.

Similar to conventional electrospinning, fused deposition modeling (FDM) has become popular because of its filamentbased additive manufacturing (AM) method, in which plastic materials in a filament form are fed into a heating nozzle, then the filament is melted, extruded, and deposited onto a build plate to generate a three-dimensional structure in a layer-bylayer fashion. ${ }^{17}$ This process can provide more multifunctional materials through custom-made filaments. ${ }^{18-21}$ Thus, FDM technology may be used to develop filaments enriched with fillers and build three-dimensional (3D) structures with dedicated applications.

In this study, biodegradable polymers PLA and PBAT were used to print biocomposite scaffolds as microalgae carrier, because of PLA with PBAT have been shown to have excellent properties and renewable and biodegradable nature. $^{22-24}$

PLA, PBAT, and Chlorella pyrenoidosa ternary biocomposites were prepared using melt blending. These biocomposites were then used to develop some custom-made adsorbent filaments that can be used for commercial FDM 3D printers. 3D printed structures were constructed, and their biosorption properties were studied. Our findings established a feasible strategy for industrial dye effluents.

\section{Materials and methods}

2.1 Materials
The commercial PLA 4032D was purchased from Nature Works. PBAT C1200 was obtained from BASF. Chlorella pyrenoidosa $(\mathrm{Cp})$ was provided by Wudi lv Qi Bioengineering Co. Ltd. (Shandong, China). Methylene blue (MB) was obtained from Sinopharm Chemical Reagent Co., Ltd (Shanghai, China) as a commercially available textile dye and was used as-received.

\subsection{Immobilization of Cp on the PLA/PBAT blend}

Both PLA and PBAT pellets were dried under vacuum at $80^{\circ}$ $\mathrm{C}$ for $12 \mathrm{~h}$ to remove moisture, and $\mathrm{Cp}$ was dried under vacuum at $60^{\circ} \mathrm{C}$ for $12 \mathrm{~h}$ prior to the melt blending. As shown in Fig. 1, the dried PLA, PBAT, and Cp were premixed on a homogenizer and extruded on a POTOP MEDI-22/40 corotating twin-screw extruder with a screw diameter of 22 mm (Guangzhou POTOP Experimental Analysis Instrument Co., Ltd., China). The temperatures along the extruder were set at $125,135,145,160,165,170,170,170,155$, and $145^{\circ} \mathrm{C}$ from the feed zone to the die. The rotation speed of the screw was set to be $200 \mathrm{rpm}$. The strap of blends was cooled, granulated and dried in a vacuum oven at $60{ }^{\circ} \mathrm{C}$ overnight. The mass ratio of PLA/PBAT was fixed at $80 / 20$, and the composite was denoted as PIBCPx, which $\mathrm{x}$ represents the dosage of $\mathrm{Cp}$.

\subsection{Preparation of biofilaments}

The dried PIBCPx was employed a raw material to fabricate filament on a two heating zone mini filament system (Wellzoon Type C, Shenzhen Mistar Technology Co., Ltd., China). The extrusion temperatures were set to 155 , and $175^{\circ} \mathrm{C}$, whereas the speed of the screw was set at $15 \mathrm{rpm}$. PIBCPx filaments with an average diameter of $1.75 \mathrm{~mm}$ were obtained.

\subsection{FDM printing processes}

The $3 \mathrm{D}$ printed scaffold was designed using a $3 \mathrm{D}$ CAD program. And the scaffold $(10 \mathrm{~mm}$ in length, $8 \mathrm{~mm}$ in width,

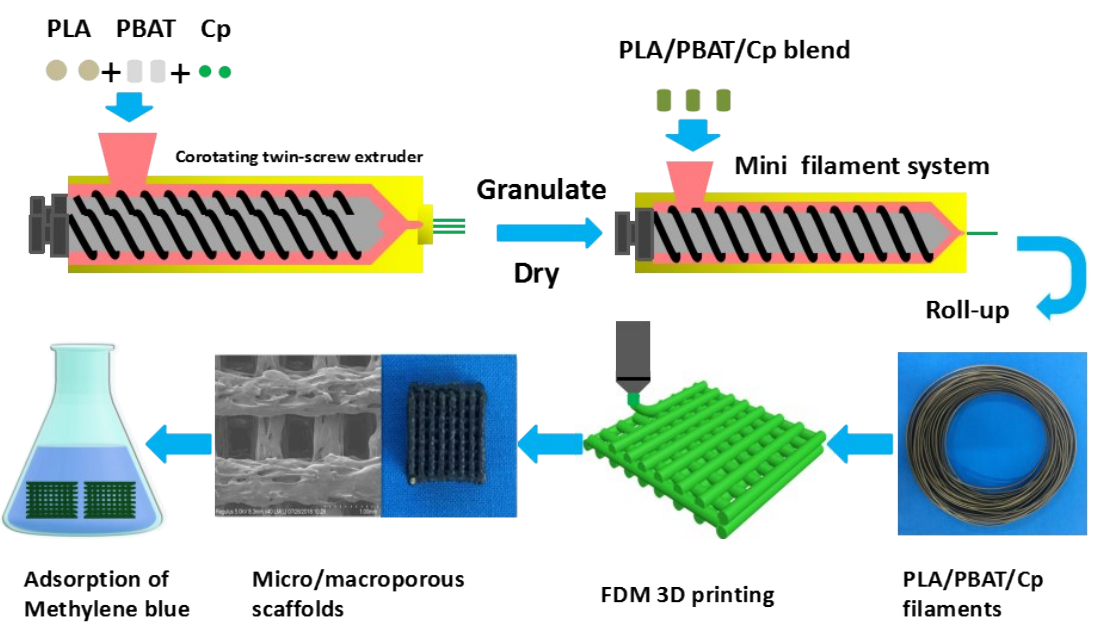

Fig. 1 Schematic diagram for immobilization of $\mathrm{Cp}$ on PLA/PBAT dimensions scaffold. 
and $8 \mathrm{~mm}$ in height; eight layers, $100 \%$ in fill, final weight of scaffold is $0.435 \mathrm{~g}$ ) was printed using the filament as a feeder on an FDM printer (MD2030, Shenzhen Sengong Technology Co., Ltd., China). The nozzle temperature was $180{ }^{\circ} \mathrm{C}$, and the platform temperature was $60^{\circ} \mathrm{C}$. The printing speed was 50 $\mathrm{mm} / \mathrm{s}$, the layer thickness was $0.2 \mathrm{~mm}$, and the nozzle diameter was $0.40 \mathrm{~mm}$. The theoretical contents of $\mathrm{Cp}$ within 3D-printed scaffolds of PIBCP0, PIBCP5, PIBCP10, PIBCP15, PIBCP20 and PIBCP30 are calculated to be $0,0.021,0.040,0.057,0.073$ and $0.100 \mathrm{~g}$, respectively.

\subsection{Characterization}

Cp, PIBCP0, and PIBCP30 were analyzed using a Thermo Scientific Nicolet 5700 FTIR Spectrometer (USA). The samples were ground with $\mathrm{KBr}$ and pressed into a pellet. The FTIR spectra were recorded in the $4000-400 \mathrm{~cm}^{-1}$ region.

Rheological measurements were conducted in small amplitude oscillatory frequency sweep mode on a stresscontrolled rheometer (DHR-2, TA Instruments). The frequency sweeps were performed within the range of $0.1 \mathrm{rad} / \mathrm{s}$ to $625 \mathrm{rad} /$ $\mathrm{s}$ at $180^{\circ} \mathrm{C}$. All sweeps were conducted at a strain of $1 \%$.

The tensile strength and notched impact strength were tested on a universal testing machine SANS-CMT5105 (Shenzhen Sans Testing Machine Co., Ltd., China) and a pendulum impact testing machine (Shenzhen Sans Testing Machine Co., Ltd., China) in accordant with GB/T1040.2/1A2006 (ISO527-2/1A:1993) and GB/T1043.1-2008 (ISO179-1: 2000), respectively.

The morphology of various PIBCPx were analyzed on a JSM-7500F scanning electron microscope (JEOL, Japan), with an acceleration voltage of $10 \mathrm{kV}$. The Energy Dispersive Spectrometer (EDS) study of the PIBCP30 was observed on a scanning electron microscope (SEM, Hitachi 8100). PIBCP30 morphology was examined by transmission electron microscopy (TEM, JEM 2010, JEOL).

\subsection{Adsorption performance of PIBCPx}

Biosorption experiments were carried out by mixing 3D printed scaffolds into $50 \mathrm{~mL} \mathrm{MB}$ solutions with various initial concentrations in a serials Erlenmeyer flasks. The flasks were shaken in a speed of $250 \mathrm{rpm}$ at desired temperature. And the dye concentration was determined at desired time using a UV spectrophotometry (UV-1750; Shimadzu) at a wavelength of $664 \mathrm{~nm}$. The adsorption isotherms and the biosorption kinetics were discussed. The adsorption rate and adsorption quantity of dye onto PIBCPx were calculated by applying Eq. (1) and (2), respectively:

$$
\begin{aligned}
& R(\%)=\frac{C_{0}-C_{e}}{C_{0}} \times 100 \% \\
& q_{e}=\frac{\left(C_{0}-C_{e}\right)}{m} \times V
\end{aligned}
$$

where $\mathrm{R}$ and qe are the adsorption rate and amount of dye taken up by the PIBCPx , respectively $(\mathrm{mg} / \mathrm{g}), \mathrm{C}_{0}$ and $\mathrm{C}_{\mathrm{e}}$ are the initial and equilibrium concentrations of the dyes, respectively $(\mathrm{mg} / \mathrm{L}), \mathrm{V}$ is the volume of the MB solution $(\mathrm{L})$, and $\mathrm{m}$ is the weight of the PIBCPx used (two PIBCPx scaffold $=0.87 \mathrm{~g}$ ).

\subsection{Reusability experiments for PIBCP30}

In order to investigate the recyclability of the $3 \mathrm{D}$ printed scaffolds, adsorption-desorption cycles of $\mathrm{MB}$ on the 3D printed PIBCP30 scaffolds were carried out. The adsorption run was performed in a conditions of $0.87 \mathrm{~g}$ adsorbent, $50 \mathrm{~mL}$ MB solution with an initial concentration of $100 \mathrm{mg} / \mathrm{L}$, and adsorption time of $24 \mathrm{~h}$. The desorption run was performed after the equilibrium adsorption. The equilibrium adsorbed 3D printed scaffold was separated from the MB solution and put into $50 \mathrm{ml} 0.5 \mathrm{mM} \mathrm{HCl}$ solution with ultrasound treatment for $60 \mathrm{~min}$. The process was not repeated until no MB determined in the $\mathrm{HCl}$ solution. The desorbed 3D printed scaffold then was washed with distill water and used as adsorbent in the next adsorption-desorption cycle.

\section{Results and Discussion}

\subsection{Rheology and mechanical properties}

The effect of $\mathrm{Cp}$ on the complex viscosity $\left(\eta^{*}\right)$ of PLA/PBAT blends is presented in Fig. 2a. It is clear that $\eta^{*}$ decrease with increases in the amount of $\mathrm{Cp}$ up to a critical concentration ( $\leqslant$ $10 \mathrm{phr}$ ) in the low-frequency range, indicating that the presence of $\mathrm{Cp}$ is able to act as a diluent and plasticizer for the PLA/ PBAT blend. With raising the amount of $\mathrm{Cp}$, the complex viscosity of the biocomposites blend gradually increases in the low-frequency range because of the presence of $\mathrm{Cp}$ leading to enhance the interaction between PLA and PBAT phases. The filler-polymer and filler-filler interactions lead to an increase in the complex viscosity, more pronounced shear-thinning behavior. $^{24}$

The storage modulus $\left(\mathrm{G}^{\prime}\right)$ of PIBCPx blends as a function of frequency are illustrated in Fig. 2b. It is observed that with the incorporation of $\mathrm{Cp}$, the $\mathrm{G}^{\prime}$ values of blend melt (except 5 phr content) increase at low frequencies. The higher absolute values of $\mathrm{G}^{\prime}$ indicate that the presence of $\mathrm{Cp}$ contributes to enhancing the modulus of the PLA/PBAT blend. The blend gives a solid-like behavior, revealing that the possible development of a network structure that can be associated with the existence of a yield stress. ${ }^{25,26}$ At a high frequency region, the $G^{\prime}$ of PIBCPx blend is lower than that of PIBCP0, indicating that intensive shearing destroys the network structure with the presence of Cp.

Fig. 2c shows tensile strength and notched impact strength values of various $\mathrm{Cp}$ filled PIBCPx blends. It is evident that the tensile strength and notched impact strength of PIBCPx blend decrease with increasing in the dosage of $\mathrm{Cp}$. It is suggested that PLA, PBAT and Cp are thermodynamically 

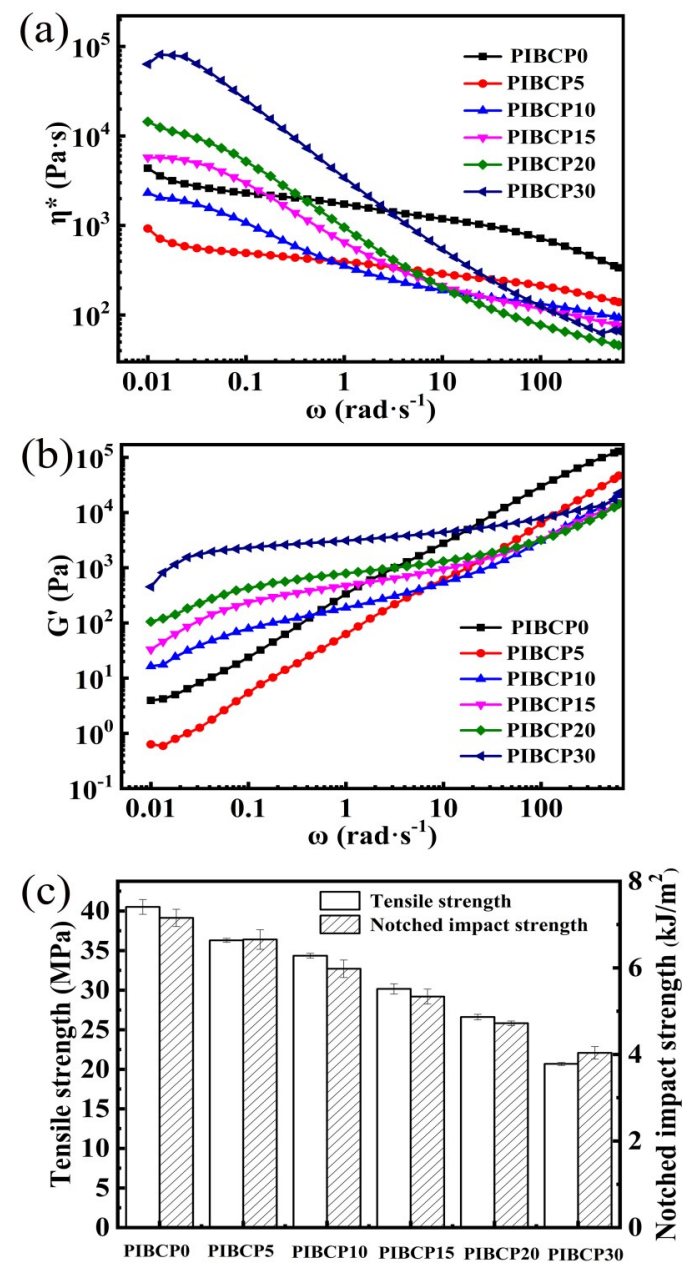

Fig. 2 (a) Complex viscosity $\left(\eta^{*}\right)$, (b) modulus $\left(G^{\prime}\right)$ of the PIBCPx biocomposites immobilized with various concentrations of $\mathrm{Cp}$ and (c) Effect of $\mathrm{Cp}$ content on the mechanical properties of PIBCPx. immiscible due to the difference of their hydrophilicities. The incompatibility between the Cp and PLA/PBAT polymers in the blend system resulting in phase separation and deterioration in mechanical properties. ${ }^{27}$ The tensile strength and notched impact strength of PIBCP 30 clearly reduce to $22 \mathrm{MPa}$ and $4 \mathrm{~kJ} /$ $\mathrm{m}^{2}$, respectively. However, the tensile strength is still higher than that of pristine PBAT (i.e., $11.03 \mathrm{MPa})^{27}$ and the notched impact strength is still higher than that of pristine PLA (i.e., $\left.2.11 \mathrm{~kJ} / \mathrm{m}^{2}\right),{ }^{27}$ suggesting that the mechanical property of $\mathrm{Cp}$ immobilized PLA/PBAT biocomposite can be tailored to meet the requirements of large-scale wastewater treatment applications.

\subsection{Microscopic analysis results of 3D printed scaffolds}

Surface images of the PIBCPx 3D-printed stripes in the scaffold are shown in Fig. 3. The surface of the PLA/PBAT blend (PIBCP0) is smooth and compact (Fig. 3a). It is clear that the increment of $\mathrm{Cp}$ content leads to decreasing the diameter and increasing roughness and porosity of of the 3Dprinted scaffold. These may be caused by the thermodynamical immiscibility of PLA/PBAT blend and Cp due to their different hydrophily.

To determine the distribution of microalgae in the scaffold of PIBCP30, TEM and EDS measurements are carried out. As shown in Fig. 4a, microalgae appeared in the form of irregular fragments $0.5 \mu \mathrm{m}$ in width and $0.5-1 \mu \mathrm{m}$ in length. As obviously seen, there was a distinct separation between these microalgae irregular fragments with a little aggregation. Fig. $4 \mathrm{~b}$-e shows the EDS mappings of the PIBCP30 surface. It can be seen that five elements including $\mathrm{C}, \mathrm{N}, \mathrm{O}, \mathrm{P}$, and $\mathrm{S}$ existed in the PIBCP30. Typically, the N, P, and S elements belonged to microalgae fragments, the $\mathrm{C}$ and $\mathrm{O}$ elements belonged to
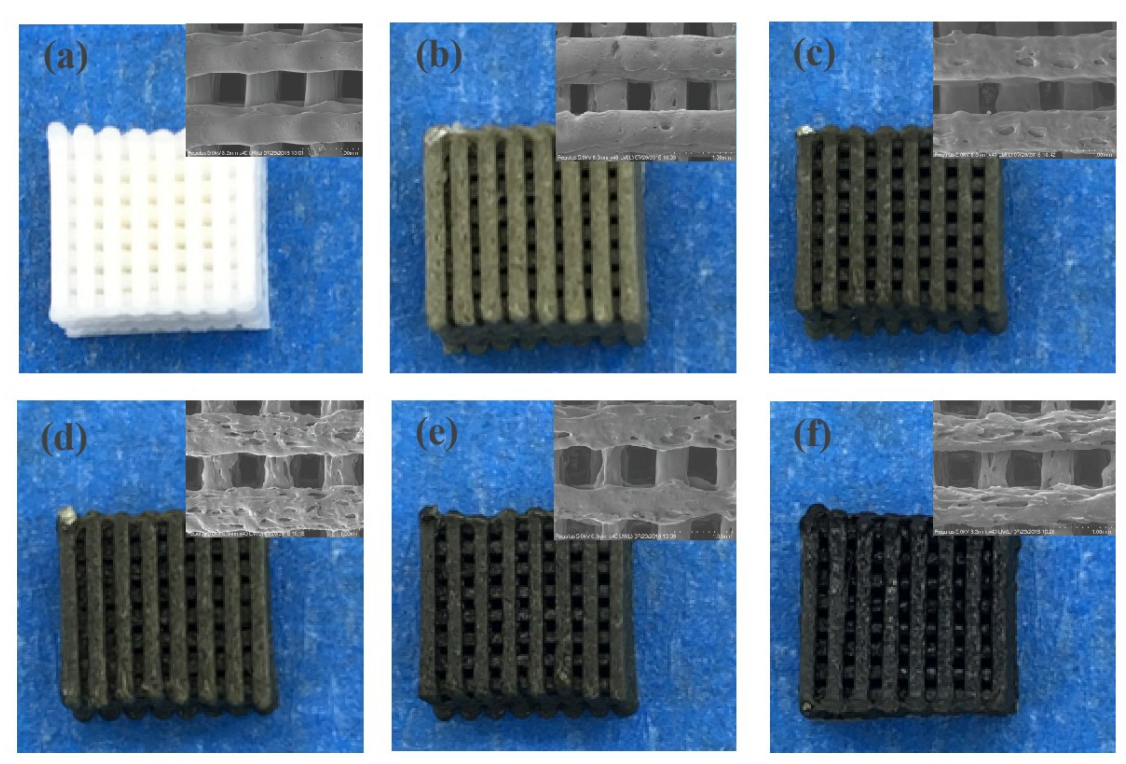

Fig. 3 SEM images of (a) PIBCP0, (b) PIBCP5, (c) PIBCP10, (d) PIBCP15, (e) PIBCP20, and (f) PIBCP30 3D printed scaffolds $(40 \times$ magnification $)$. 


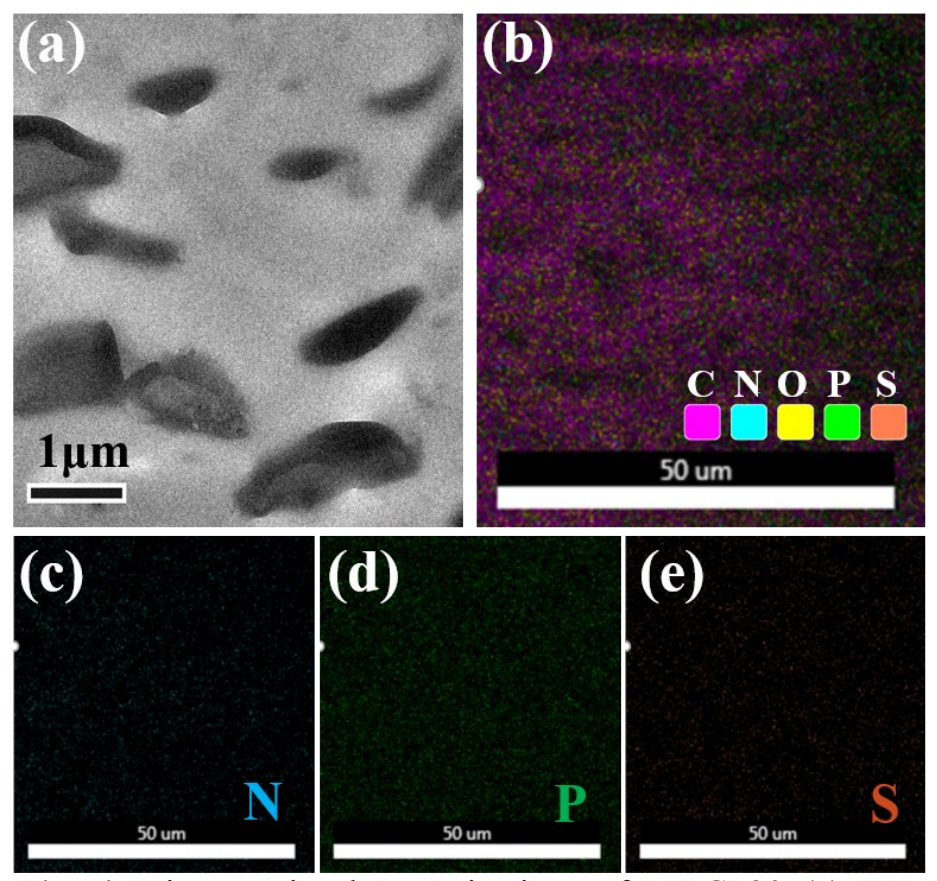

Fig. 4 Microscopic characterizations of PIBCP30 (a) TEM images, and (b-e) SEM-EDS element mappings for N, P, and S of the PIBCP30 before MB adsorption.

PLA/PBAT matrix. EDS reveals that the microalgae fragments was well dispersed in the polymer matrix.

\subsection{Adsorption performance of PIBCP30}

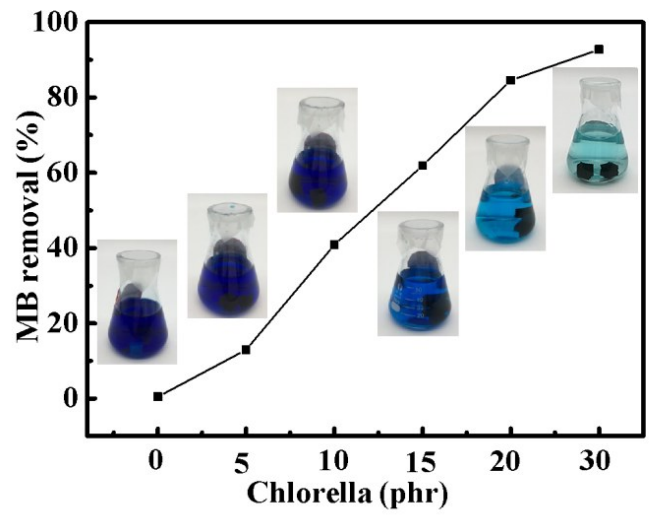

Fig. 5 Removal efficiency of MB solution using PIBCPx. Conditions: initial $\mathrm{MB}$ concentration, $100 \mathrm{mg} / \mathrm{L}$; mass of adsorbent, two immobilization scaffolds with different $\mathrm{Cp}$ contents; temperature, $298.15 \mathrm{~K}$; contact time, $24 \mathrm{~h}$.

The effects of various PIBCPx scaffolds on MB removal efficiency are shown in Fig. 5. MB removal efficiency increases with increasing $\mathrm{Cp}$ content in PIBCPx scaffold. PIBCP30 possesses $92.66 \%$ MB removal efficiency whereas PIBCP0 has $0.06 \%$ at the adsorption time of $24 \mathrm{~h}$. It is proposed that high $\mathrm{Cp}$ dosage in the scaffold causes to more exposure of active sites for $\mathrm{MB}$ adsorption. ${ }^{28}$

The effects of initial $\mathrm{pH}$ on the percentage of $\mathrm{MB}$ removal on the PIBCP30 scaffold were evaluated. The result is shown in Fig. 6a. It is evidence that increasing the solution $\mathrm{pH}$ leads to increasing $\mathrm{MB}$ adsorption efficiency due to more $\mathrm{MB}$ binding sites exposure for $\mathrm{MB}$ cations adsorption at higher $\mathrm{pH}$ value. The aqueous solution $\mathrm{pH}$ is expected to influence the adsorptive uptake of dyes due to its impact on both the surface binding-sites of the adsorbent and the ionization process of the dye molecule. ${ }^{29}$ In this study, it is suggested that the availability of negative charged binding sites increases attraction of $\mathrm{MB}$ cations and allowing biosorption onto the $\mathrm{Cp}$ surface in the $3 \mathrm{D}$ printed scaffold.

The effect of ionic strength on the adsorption capacity of $\mathrm{MB}$ onto PIBCP30 scaffold were studied at $0.02-1 \mathrm{~mol} / \mathrm{L} \mathrm{NaCl}$ concentrations at $25^{\circ} \mathrm{C}$ and the results are given in Fig. 6b. As shown in Fig. 6b, increasing ionic strength results in significantly decreasing the adsorption capacity of $\mathrm{MB}$ on PIBCP30 scaffold. The results can be explained as follows. ${ }^{30}$ 1) The occurrence of electrostatic competition between $\mathrm{Na}$ ion and the cationic dye molecules inhibits the electrostatic interaction. ${ }^{31}$ 2) The presence of salt causes an increase in the degree of dissociation of the dye molecules by facilitating the protonation. ${ }^{32}$ And 3 ) various ions and organic matter in the solution prevent the diffusion of the adsorbate to the active sites. $^{18}$

\subsection{Adsorption kinetics}

The adsorption kinetics experiment of $\mathrm{MB}$ with different initial concentrations $(50,100,200 \mathrm{mg} / \mathrm{L})$ on the PIBCP30 scaffold were performed at $298.15 \mathrm{~K}$. The results are given in Fig. 7. 

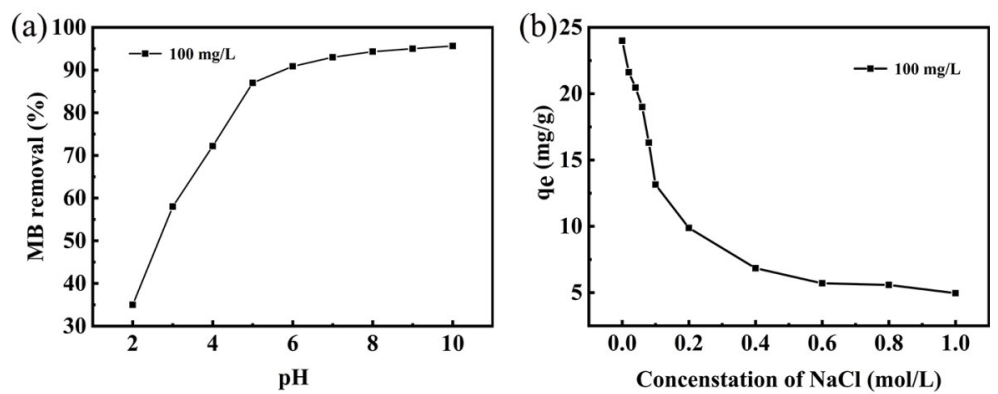

Fig. 6 Effects of (a) initial $\mathrm{pH}$ and (b) ionic strength on the adsorption of $\mathrm{MB}$ on PIBCP30. Conditions: initial MB concentration: $100 \mathrm{mg} / \mathrm{L}$; mass of adsorbent: two immobilization scaffold with $0.20 \mathrm{~g} \mathrm{Cp}$; temperature: $298.15 \mathrm{~K}$; contact time: $24 \mathrm{~h}$.
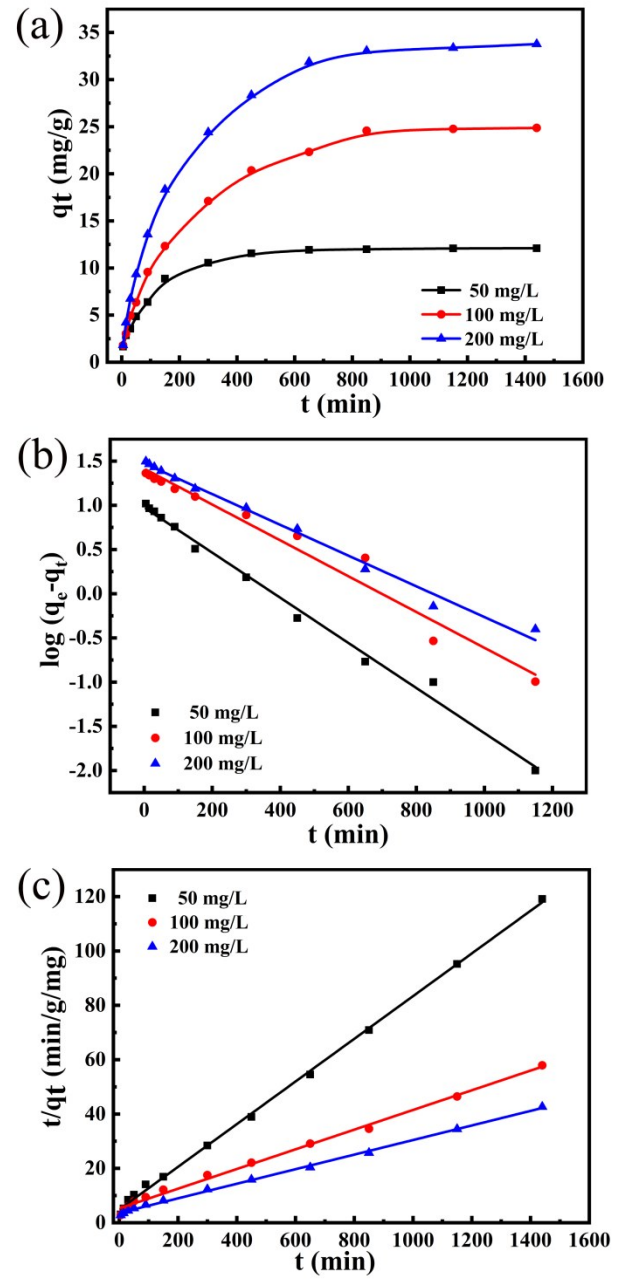

Fig. 7 (a) Effects of contact time on adsorption of MB on PIBCP30. (b) Pseudo-first; (c) pseudo-second.

Adsorption kinetics are critical for analyzing the adsorption process and mechanis. ${ }^{33}$ In Fig. 7, the adsorptive mass increases rapidly at initial time $(200 \mathrm{~min})$ and then reaches near saturation at over $800 \mathrm{~min}$. The pseudo-first-order and pseudosecond-order models were applied to fit the experimental data for $\mathrm{MB}$ adsorption process and the calculated parameters are tabulated in Table 1 . The correlation coefficient $\left(\mathrm{R}^{2}\right)$ for pseudosecond-order kinetic model is more than 0.99 , whereas those for the pseudo first-order are ranged in 0.9667-0.9922, suggesting that pseudo-second-order is a better model to analyze the experimental data in the linearized form (Figs. 7bc) than the pseudo-first-order kinetic model. Accordingly, the adsorption rate determining step is suggested to be not the external diffusion of MB from the bulk liquid to the PIBCP30 surface but the chemisorption steps due to the presence of active sites. The similar conclusions have been proposed for adsorption of dyes on some biosorbents. ${ }^{34-36}$

\subsection{Adsorption isotherm}

The Langmuir and Freundlich models were employed to describe the adsorption experimental data. The adsorption isotherms are shown in Fig. 8 and the parameters are listed in Table 2. As shown in Fig. 8a, all isotherms for MB adsorption on PIBCP30 at different temperatures are of the L-type, with a sharp knee and a fairly horizontal plateau, indicating that the adsorption of MB onto PIBCP30 is site-specific and thus represents a monolayer. ${ }^{37,38}$

In Table 2, the correlation coefficients $\left(\mathrm{R}^{2}\right)$ for Langmuir isotherm model and Freundlich one are in the ranges of 0.9958 0.9992 and $0.9336 \sim 0.9860$, respectively, indicating that the Langmuir isotherm model fitted better to our isotherm experimental results than the Freundlich isotherm model (Figs. $8 \mathrm{~b}$ and c). This suggested that, despite the chemical complexity of the PIBCP30 adsorbents, their adsorption sites can be considered to be in proportion to MB adsorption capability. ${ }^{38}$ Moreover, The affinity between MB and PIBCP30 adsorbent can be predicted by a dimensionless constant separation factor $\mathrm{R}_{\mathrm{L}}$ (Table 2). ${ }^{35,39}$ These findings suggested that the adsorption of MB by PIBCP30 adsorbents is strong under our experimental conditions.

\subsection{Adsorption thermodynamics}

Fig. $8 \mathrm{~d}$ shows the plots of $\operatorname{lnK}_{\mathrm{D}}$ against $1 / \mathrm{T}$ for adsorption of $\mathrm{MB}$ onto PIBCP30. The changes in standard enthalpy $\left(\Delta \mathrm{H}^{0}\right)$, 
Table 1 Kinetic parameters for MB adsorption on PIBCP30 adsorbent.

\begin{tabular}{|c|c|c|c|c|c|}
\hline \multirow{3}{*}{ Model } & \multirow{3}{*}{ Parameter description } & \multicolumn{4}{|c|}{ Experimental data } \\
\hline & & \multirow{2}{*}{ Parameters } & \multicolumn{3}{|c|}{$\mathrm{C}_{0}(\mathrm{mg} / \mathrm{L})$} \\
\hline & & & 50 & 100 & 200 \\
\hline \multirow{4}{*}{$\begin{array}{l}\text { Pseudo-first-order model: } \\
\log \left(q_{e}-q_{t}\right)=\log q_{e}-\frac{k_{1} t}{2.303}\end{array}$} & $\begin{array}{l}\mathrm{q}_{\mathrm{e}} \text { :the maximum adsorption } \\
\text { capacity, } \mathrm{mg} / \mathrm{g}\end{array}$ & $\mathrm{q}_{\mathrm{e}, \mathrm{exp}}$ & 12.09 & 24.86 & 33.77 \\
\hline & $\begin{array}{l}\mathrm{q}_{\mathrm{t}} \text { : the amount of } \mathrm{MB} \\
\text { adsorbed at various times } \mathrm{t} \text {, } \\
\mathrm{mg} / \mathrm{g}\end{array}$ & $\mathrm{q}_{\mathrm{e}, \mathrm{cal}}$ & 9.43 & 25.90 & 29.79 \\
\hline & $\begin{array}{l}\mathrm{k} 1 \text { : the rate constant of } \\
\text { pseudo first-order adsorption, }\end{array}$ & $\mathrm{k}_{1}$ & $\begin{array}{c}0.0058 \\
7\end{array}$ & 0.00468 & 0.00401 \\
\hline & $\min ^{-1}$ & $\mathrm{R}^{2}$ & 0.9922 & 0.9667 & 0.9896 \\
\hline \multirow{4}{*}{$\begin{array}{l}\text { Pseudo-second-order model: } \\
\frac{t}{q_{t}}=\frac{1}{k_{2} q_{e}^{2}}+\frac{t}{q_{e}}\end{array}$} & \multirow{4}{*}{$\begin{array}{l}\mathrm{k}_{2}: \text { the rate constant of } \\
\text { pseudo-second- order } \\
\text { adsorption, }(\mathrm{g} /(\mathrm{mg} \cdot \mathrm{min}))\end{array}$} & $\mathrm{q}_{\mathrm{e}, \mathrm{exp}}$ & 12.09 & 24.86 & 33.77 \\
\hline & & $\mathrm{q}_{\mathrm{e}, \text { al }}$ & 12.74 & 25.6 & 36.29 \\
\hline & & $\mathrm{k}_{2}$ & $\begin{array}{c}0.0001 \\
3\end{array}$ & 0.000028 & 0.00002 \\
\hline & & $\mathrm{R}^{2}$ & 0.9987 & 0.9948 & 0.9980 \\
\hline
\end{tabular}

Table 2 Langmuir and Freundlich isotherm parameters for MB adsorption on PIBCP30 adsorbent.

\begin{tabular}{|c|c|c|c|c|c|}
\hline \multirow{3}{*}{ Model } & \multirow{3}{*}{ Parameter description } & \multicolumn{4}{|c|}{ Experimental data } \\
\hline & & \multirow[t]{2}{*}{ Parameters } & \multicolumn{3}{|c|}{ Temperature $(\mathrm{K})$} \\
\hline & & & 298.15 & 308.15 & 318.15 \\
\hline & $\mathrm{qm}$ : the Langmuir constants related to & $\mathrm{qm}$ & 35.21 & 40.85 & 43.80 \\
\hline Langmuir isotherm: & sorption capacity, mg/g. & $1-T$ & 020 & 057 & 094 \\
\hline$\frac{C_{e}}{=}=1+\frac{C_{e}}{x}$ & & & & & \\
\hline$q_{e} \quad k_{L} q_{\mathrm{m}} \quad q_{\mathrm{m}}$ & $\begin{array}{l}\mathrm{kL}: \text { the Langmuir constants related } \\
\text { toenergy of sorption, } \mathrm{L} / \mathrm{mg} \text {. }\end{array}$ & $\mathrm{R} 2$ & 0.9958 & 0.9985 & 0.9992 \\
\hline Freundlich isotherm. & $\mathrm{kF}$ : the Freundlich constants related to & $\mathrm{kF}$ & 12.76 & 15.23 & 17.30 \\
\hline ค & & $1 / \mathrm{n}$ & 0.2336 & 0.2298 & 0.2290 \\
\hline $\log q_{e}=\log k_{F}+\frac{1}{n} \log C_{e}$ & $\begin{array}{l}1 / \mathrm{n} \text { : the Freundlich constants related to } \\
\text { intensity. }\end{array}$ & $\mathrm{R} 2$ & 0.9860 & 0.9692 & 0.9336 \\
\hline dimensionless constant & $\mathrm{C} 0$ :the initial MB concentration, $\mathrm{mg} / \mathrm{L}$. & & & & \\
\hline$R_{L}=\frac{1}{\left(1+k_{L} C_{0}\right)}$ & $\begin{array}{l}\mathrm{RL}>1 \text {, unfavorable; } \mathrm{RL}=1 \text {, linear; } 0< \\
\mathrm{RL}<1 \text {, favorable; and } \mathrm{RL}=0, \\
\text { irreversible. }\end{array}$ & RL & 0.09 & 0.08 & 0.06 \\
\hline
\end{tabular}


Table 3 Thermodynamic parameters of MB adsorption.

\begin{tabular}{cccc}
\hline Temperature $(\mathrm{K})$ & $\Delta \mathrm{G}(\mathrm{kJ} / \mathrm{mol})$ & $\Delta \mathrm{H}(\mathrm{kJ} / \mathrm{mol})$ & $\Delta \mathrm{S}(\mathrm{kJ} / \mathrm{mol} \mathrm{K})$ \\
\hline 298 & -4.726 & & \\
308 & -7.034 & 61.291 & 0.221 \\
318 & -9.155 & & \\
\hline
\end{tabular}

(a)

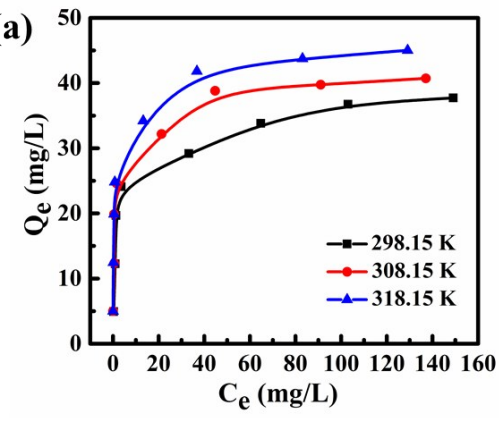

(c)

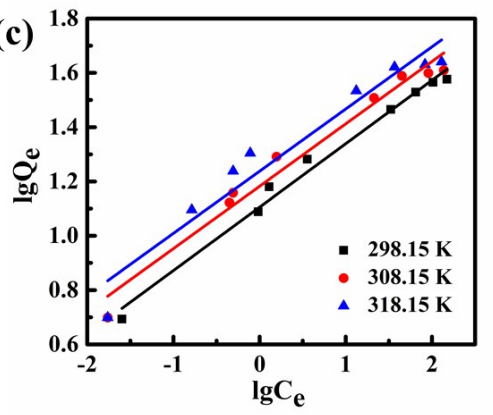

(b)

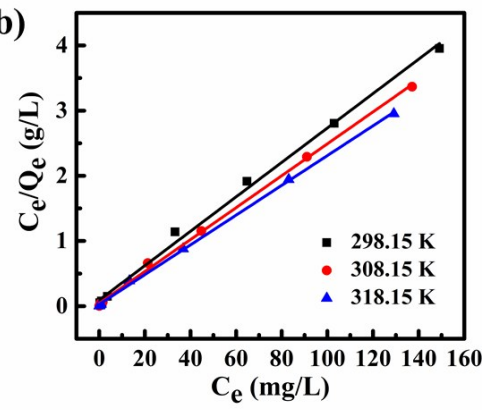

(d)

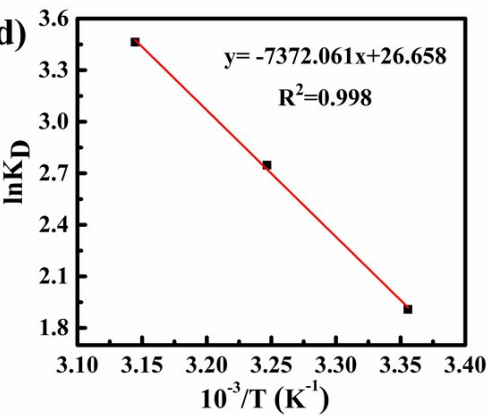

Fig. 8 Isotherms (a), Langmuir plots (b), Freundlich plots (c), and plot of $\operatorname{lnKD}$ versus $1 / \mathrm{T}$ for $\mathrm{MB}$ adsorption onto PIBCP30 at different temperatures $(\mathrm{d})$.

entropy $\left(\Delta \mathrm{S}^{0}\right)$ and free energy $\left(\left(\Delta \mathrm{G}^{0}\right)\right.$ were determined as follows: ${ }^{40}$

$$
\begin{gathered}
\ln K_{D}=\frac{\Delta G}{R T}=\frac{\Delta S}{R}-\frac{\Delta H}{R T} \\
\Delta G=-R T \ln K_{D}
\end{gathered}
$$

where $K_{D}$ is the distribution coefficient, $T$ is temperature $(K)$, and $\mathrm{R}$ is the universal gas constant $(8.314 \mathrm{~J} / \mathrm{mol} \mathrm{t})$. The values of $\Delta \mathrm{H}^{0}$ and $\Delta \mathrm{S}^{0}$ were calculated and listed in Table 3.

As shown in Table 3, the negative values of $\Delta \mathrm{G}^{0}(-4.73$, -7.03 and $-9.16 \mathrm{~kJ} / \mathrm{mol}$ at 298,308 and $318 \mathrm{~K}$, respectively) confirms the spontaneous nature and feasibility of the adsorption. ${ }^{41,42}$ High temperature causes more negative in the $\Delta G^{0}$ values indicates that the most favorable condition for higher adsorption efficiency is temperature. ${ }^{43}$ It is generally considered that the physical sorption get dominate at the $\Delta$ $\mathrm{H}^{0}$ value less than $25 \mathrm{~kJ} / \mathrm{mol}$, whereas the chemical sorption become dominate when the $\Delta \mathrm{H}^{0}$ values greater than $40 \mathrm{~kJ} / \mathrm{mol}^{44}$ Accordingly, the MB adsorption onto PIBCP30 is a chemical adsorption and endothermic reaction due to it giving a $\Delta$ $\mathrm{H}^{0}$ value of $61.29 \mathrm{~kJ} / \mathrm{mol}$. Additionally, the positive $\Delta \mathrm{S}^{0}$ value
$(0.22 \mathrm{~kJ} / \mathrm{mol})$ reflects structure changes in the adsorbent and adsorbate and increases randomness at the solid-solution interface during fixation of $\mathrm{MB}$ onto the active sites of PIBCP $30{ }^{42,45}$

\subsection{Reusability}

Reusability of a sorbent is crucial in industrial practice for dye removal from wastewater effluent and is necessary for green chemistry and cleaner production. ${ }^{46-49}$ The adsorptiondesorption of MB onto the PIBCP30 scaffold was performed for six runs and the results are shown in Fig. 9. It is clear that although the MB adsorption capability of the PIBCP30 scaffold decreases slightly in each adsorption-desorption run, it keep at $72 \%$ after six cycles. This demonstrated that the PIBCP30 scaffold has excellent recyclability for MB removal. The adsorbent is a better candidate for water decolorization than free microalgal cells ${ }^{13}$ due to its simplicity of use, reusability, and excellent mechanical properties. It is an available approach to apply on the large-scale treatment of wastewater in future. 


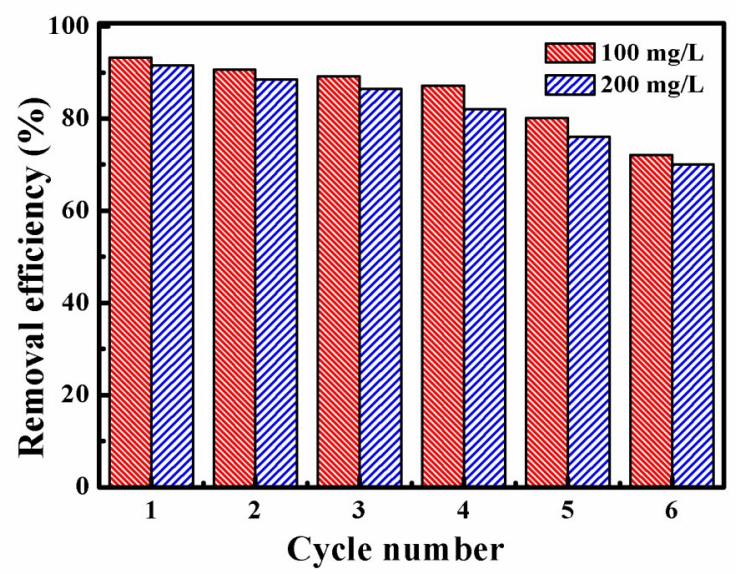

Fig. 9 Recycling study of PPC30 in removal of MB (solution $\mathrm{pH}, \mathrm{MB}$ solutions with 100 or $200 \mathrm{mg} / \mathrm{L}$ dye, two immobilization scaffolds with $0.20 \mathrm{~g} \mathrm{Cp}$ ).

\subsection{Adsorption mechanism}

The FTIR spectra of Cp, PIBCP0, PIBCP30 and are performed and studied to gain insight into the adsorption mechanism, as shown in Fig. 10. For Cp, a broad band observed at about 3420 $\mathrm{cm}^{-1}$ is assigned to $-\mathrm{OH}$ and $-\mathrm{NH}$ stretching vibrations of carbohydrates, proteins and lipids in Chlorella pyrenoidosa. Strong peaks at $1655 \mathrm{~cm}^{-1}(\mathrm{C}=\mathrm{O}$ stretching $)$ and $1542 \mathrm{~cm}^{-1}(\mathrm{~N}-$ $\mathrm{H}$ deformation) is attributed to amide I and amide II vibrational modes of proteins, respectively. ${ }^{50}$ The bands at $635 \mathrm{~cm}^{-1}$ is due to the thioethers (C-S stretch). The bands observed at 1081 $\mathrm{cm}^{-1}$ could be assigned to C-H-C to the alkyl-substituted ether, $\mathrm{C}-\mathrm{O}$ stretching. The peak at $1384 \mathrm{~cm}^{-1}$ suggest the presence of phosphodiesters in Chlorella pyrenoidosa.
For the PLA/PBAT blend (sample PIBCP0), the wide and strong absorption peak at $3450 \mathrm{~cm}^{-1}$ is assigned to hydrogen bonding of $-\mathrm{OH}$. The absorption peaks at 2995 and 2945 $\mathrm{cm}^{-1}$ are attributed to $\mathrm{C}-\mathrm{H}$ deformation (symmetric and asymmetric bends). In the carbonyl region of FTIR spectrum, the stretching vibration peak of the carbonyl group in the ester group at $1759 \mathrm{~cm}^{-1}$, and the peak at $1457 \mathrm{~cm}^{-1}$ is caused by the bending vibration of the methyl group..$^{51}$ The sharp peak at 720 $\mathrm{cm}^{-1}$ represents four or more adjacent methylene $\left(-\mathrm{CH}_{2^{-}}\right)$ groups. Bending peaks of the benzene substitutes are located between 700 and $900 \mathrm{~cm}^{-1} .{ }^{2}$

For PIBCP30, the -OH stretching vibration absorption peak is wide and strong and gives an obvious red shift. Notably, the $\mathrm{C}=\mathrm{O}$ stretching vibration absorption peak of the protein in the $\mathrm{Cp}$ appears at $1655 \mathrm{~cm}^{-1}$, and the deformation vibration absorption peak of the amide $\mathrm{N}-\mathrm{H}$ in the $\mathrm{Cp}$ protein is at $1545 \mathrm{~cm}^{-1}$. Thus, the twin-screw melt blending extrusion, single-screw filament extrusion, and $3 \mathrm{D}$ printing process can not destroy the functional groups of $\mathrm{Cp}$, which may facilitate subsequent adsorption of MB.

It could be seen from the FTIR spectrum of PIBCP30-MB in Fig. 10c, the absorption peaks of PIBCP30 at $3318 \mathrm{~cm}^{-1}$, $1655 \mathrm{~cm}^{-1}$ and $1545 \mathrm{~cm}^{-1}$ corresponding to $\mathrm{O}-\mathrm{H}, \mathrm{C}=\mathrm{O}$ and $\mathrm{N}-$ $\mathrm{H}$ stretching slightly shifted to $3312 \mathrm{~cm}^{-1}, 1650 \mathrm{~cm}^{-1}$ and 1538 $\mathrm{cm}^{-1}$, respectively, indicating the negatively charged oxhydryl, carboxyl and ammonium groups of PIBCP30 played a role in the adsorption of MB through electrostatic interaction, van der waal's forces and hydrogen bond, etc. ${ }^{53-55}$

The possible adsorption mechanism, including the adsorption process and the interactions between PIBCP30 and MB, was schematically illustrated in Fig. 11.
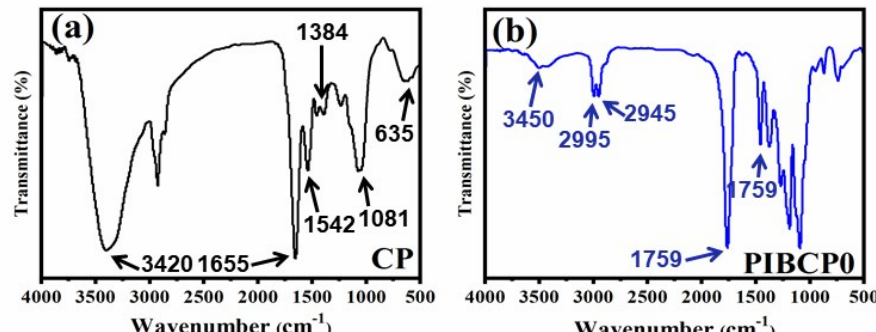

Wavenumber $\left(\mathrm{cm}^{-1}\right)$

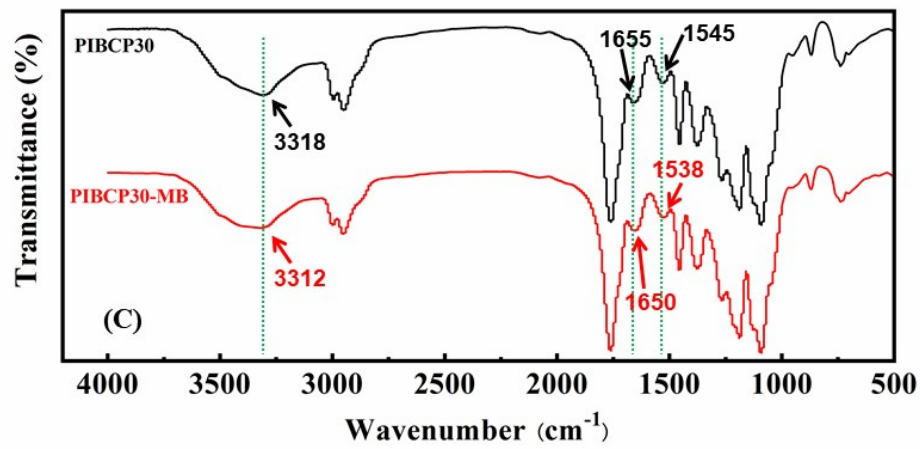

Fig. 10 Fourier transform infrared spectra of $\mathrm{Cp}, \mathrm{PIBCP0}$, PIBCP30, and PIBCP30-MB. 


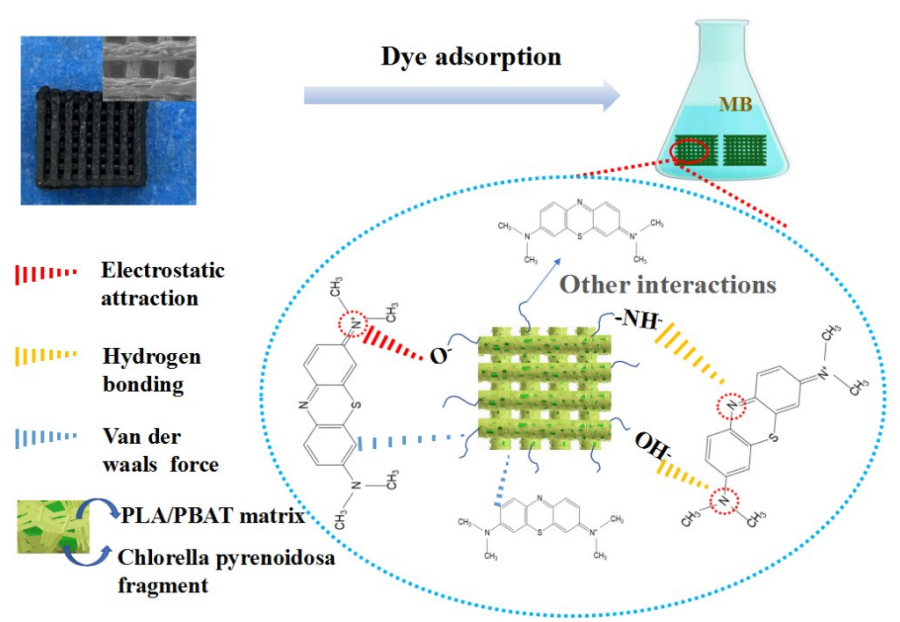

Fig. 11 Schematic adsorption mechanism of MB molecules by PIBCP30 3D printed scaffolds.

\section{Conclusion}

Various 3D-printing PIBCP scaffolds with different $\mathrm{Cp}$ concentrations are fabricated and employed as biosorbents for MB removal from aqueous solution. It is concluded that the resultant scaffold with $30 \mathrm{phr} \mathrm{Cp}$ shows available for MB removal and the mechanical features of the scaffold is high enough to its adsorbent application. The adsorption of MB onto 3D-printing PIBCP30 scaffold is found to fit the pseudosecond-order model better than the pseudo-first-order one, indicating the chemisorption of the process. The Langmuir isotherm model describs the experimental data very well, suggesting the adsorption of MB on the surface PIBCP30 scaffold occurs mainly by monolayer. Besides, $\mathrm{MB}$ adsorption onto PIBCP30 scaffold is determined to be a spontaneous and endothermic process. The adsorption-desorption of MB onto the PIBCP30 scaffold was carried out for six runs to evaluate the reusability of the adsorbent. The MB decolorization capacity of PIBCP30 scaffold keeps at $72 \%$ after six runs, indicating that of the PIBCP30 scaffold possesses an excellent reusability for MB removal. Overall, 3D-printing technique is an available approach to prepare biosorbent for the large-scale wastewater treatment application.

\section{Acknowledgments}

This work was financially supported by National Natural Science Foundation of China (NSFC 21875037) and National Key Research and Development Program of China (2016YFB0302303).

\section{References}

1. P. Luo, Y. F. Zhao, B. Zhang, J. D. Liu, Y. Yang and J. F. Liu, Water Res., 2010, 44, 1489-1497.

2. M. Rafatullah, O. Sulaiman, R. Hashim and A. Ahmad, J. Hazard. Mater., 2010, 177, 70-80.

3. N. F. Cardoso, R. B. Pinto, E. C. Lima, T. Calvete, C. V. Amavisca, B. Royer,
M. L. Cunha, T. H. M. Fernandes and I. S. Pinto, Desalination, 2011, 269, 92-103.

4. F. M. Machado, C. P. Bergmann, T. H. M. Fernandes, E. C. Lima, B. Royer, T. Calvete and S. B. Fagan, J. Hazard. Mater., 2011, 192, 1122-1131.

5. N. Isa and Z. Lockman, Environ. Sci. Pollut. Res., 2019, 26, 11482-11495.

6. Y. Xu, Y. G. Liu, S. B. Liu, X. F. Tan, G. M. Zeng, W. Zeng, Y. Ding, W. C. Cao and B. H. Zheng, Environ. Sci. Pollut. Res., 2016, 23, 23606-23618.

7. Y. Y. Han, X. D. Wu, X. X. Zhang, Z. H. Zhou and C. C. Lu, ACS Sustain. Chem. Eng., 2016, 4, 6322-6331.

8. Y. B. Yang, Z. M. Chen, X. D. Wu, X. X. Zhang and G. P. Yuan, Cellulose, 2018, 25, 2547-2558.

9. M. J. Puchana-Rosero, E. C. Lima, S. Ortiz-Monsalve, B. Mella, D. da Costa, E. Poll and M. Gutterres, Environ. Sci. Pollut. Res., 2017, 24, 42004209.

10. B. Volesky, Water Res., 2007, 41, 4017-4029.

11. F. Pagnanelli, N. Jbari, F. Trabucco, M. E. Martinez, S. Sánchez and L. Toro, Chem. Eng. J., 2013, 231, 94-102.

12. H. S. Shao, Y. W. Li, L. C. Zheng, T. X. Chen and J. Liu, J. Taiwan Inst. Chem. E., 2017, 80, 525-532.

13. I. Moreno-Garrido, Bioresour. Technol., 2008, 99, 3949-3964.

14. N. O. San Keskin, A. Celebioglu, T. Uyar and T. Tekinay, Ind. Eng. Chem. Res., 2015, 54, 5802-5809.

15. H. Lee, E. Shim, H. S. Yun, Y. T. Park, D. Kim, M. K. Ji, C. K. Kim, W. S. Shin and J. Choi, Environ. Sci. Pollut. Res., 2016, 23, 1025-1034.

16. S. Vasilieva, K. Shibzukhova, A. Morozov, A. Solovchenko, I. Bessonov, M. Kopitsyna, A. Lukyanov, K. Chekanov and E. Lobakova, J. Biotechnol., 2018, 281, 31-38.

17. Q. Y. Chen, J. D. Mangadlao, J. Wallat, A. D. Leon, J. K. Pokorski and R. C. Advincula, ACS Appl. Mater. Inter., 2017, 9, 4015-4023.

18. C. E. Flores-Chaparro, L. F. C. Ruiz, M. C. A. de la Torre, M. A. Huerta-Diaz and J. R. Rangel-Mendez, J. Environ. Manage., 2017, 193, 126-135.

19. T. N. Tran, I. S. Bayer, J. A. Heredia - Guerrero, M. Frugone, M. Lagomarsino, F. Maggio and A. Athanassiou, Macromol. Mater. Eng., 2017, 302, 1700219.

20. Z. Viskadourakis, M. Sevastaki and G. Kenanakis, Appl. Phys. A-Mater., 2018, 124, 585.

21. Y. H. Zhou, X. S. Xia, X. P. Liu, B. Q. Huang, L. R. Xiao, Q. R. Qian and Q. H. Chen, Macromol. Mater. Eng., 2019, 304, 1900021.

22. R. Al-Itry, K. Lamnawar and A. Maazouz, Rheol. Acta, 2014, 53, 501-517.

23. M. A. Abdelwahab, S. Taylor, M. Misra and A. K. Mohanty, Macromol. Mater. Eng., 2015, 300, 299-311.

24. A. L. P. de L. Freitas, L. R. T. Filho, P. S. Calvão and A. M. C. de Souza, Polym. Test., 2017, 62, 189-195. 
25. S. W. Ko, R. K. Gupta, S. N. Bhattacharya and H. J. Choi, Macromol. Mater. Eng., 2010, 295, 320-328.

26. H. Moustafa, N. E. Kissi, A. I. Abou-Kandil, M. S. Abdel-Aziz and A. Dufresne, ACS Appl. Mater. Inter., 2017, 9, 20132-20141.

27. M. Kumar, S. Mohanty, S. K. Nayak and M. R. Parvaiz, Bioresour. Technol., 2010, 101, 8406-8415

28. A. S. Franca, L. S. Oliveira and M. E. Ferreira, Desalination, 2009, 249, $267-$ 272.

29. M. C. Ncibi, B. Mahjoub and M. Seffen, J. Hazard. Mater., 2007, 139, 280285 .

30. Y. Q. Hu, T. Guo, X. S. Ye, Q. Li, M. Guo, H. N. Liu and Z. J. Wu, Chem. Eng. J., 2013, 228, 392-397.

31. M. R. R. Kooh, M. K. Dahri, L. B. L. Lim, L. H. Lim and O. A. Malik, Environ. Earth Sci., 2016, 75, 783.

32. M. Doğan, Y. Özdemir and M. Alkan, Dyes Pigments, 2007, 75, 701-713.

33. C. F. Zheng, H. L. Zheng, Y. J. Wang, Y. L. Wang, W. Q. Qu, Q. An and Y. Z. Liu, Bioresour. Technol., 2018, 267, 1-8.

34. Q. R. Qian, M. Machida and H. Tatsumoto, Waste Manag., 2008, 28, $1064-$ 1071 .

35. V. Nair, A. Panigrahy and R. Vinu, Chem. Eng. J., 2014, 254, 491-502.

36. L. Q. Jin, Q. C. Sun, Q. H. Xu and Y. J. Xu, Bioresour. Technol., 2015, 197, 348-355.

37. Y. R. Lin and HsishengTeng, Micropor. Mesopor. Mat., 2002, 54, 167-174.

38. Q. R. Qian, Q. H. Chen, M. Machida, H. Tatsumoto, K. Mochidzuki and A. Sakoda, Appl. Surf. Sci., 2009, 255, 6107-6114.

39. K. R. Hall, L. C. Eagleton, A. Acrivos and T. Vermeulen, Ind. Eng. Chem. Fundam., 1966, 5, 212-223.

40. L. Chen and B. Bai, Ind. Eng. Chem. Res., 2013, 52, 15568-15577.

41. M. Auta and B. H. Hameed, Chem. Eng. J., 2014, 237, 352-361.

42. J. Fu, Z. Chen, M. Wang, S. Liu, J. Zhang, J. Zhang, R. Han and Q. Xu,
Chem. Eng. J., 2015, 259, 53-61.

43. A. A. A. Darwish, M. Rashad and H. A. AL-Aoh, Dyes Pigments, 2019, 160, 563-571.

44. V. K. Gupta, D. Pathania, S. Agarwal and S. Sharma, Environ. Sci. Pollut. Res., 2013, 20, 2632-2644.

45. R. L. Liu, Y. Liu, X. Y. Zhou, Z. Q. Zhang, J. Zhang and F. Q. Dang, Bioresour. Technol., 2014, 154, 138-147.

46. M. D. Victor-Ortega, J. M. Ochando-Pulido and A. Martinez-Ferez, Sep. Purif. Technol., 2017, 173, 1-8.

47. E. I. Unuabonah, F. O. Agunbiade, M. O. Alfred, T. A. Adewumi, C. P. Okoli, M. O. Omorogie, M. O. Akanbi, A. E. Ofomaja and A. Taubertd, J. Clean. Prod., 2017, 164, 652-663.

48. X. Zhou, Y. Yang, C. Li, Z. Yang, W. BenYang, Z. Q. Tian, L. M. Zhang and TaoTao, J. Clean. Prod., 2018, 203, 655-663.

49. A. R. Soleymani, M. Mahdiei and M. Haerifar, J. Clean. Prod., 2019, 211, 1328-1338.

50. J. N. Murdock and D. L. Wetzel, Appl. Spectrosc. Rev., 2009, 44, 335-361.

51. Y. J. Jin, S. Men and Y. X. Weng, J. Polym. Eng., 2018, 38, 223-229.

52. R. Al-Itry, K. Lamnawar and A. Maazouz, Polym. Degrad. Stab., 2012, 97, 1898-1914.

53. S. Fan, Y. Wang, Z. Wang, J. Tang, J. Tang and X. Li, J. Environ. Chem. Eng., 2017, 5, 601-611.

54. K. Song, H. Xu, L. Xu, K. Xie and Y. Yang, Bioresour. Technol., 2017, 232, 254-262.

55. M. Yan, W. Huang and Z. Li, Int. J. Biol. Macromol., 2019, 136, 927-935.

Publisher's Note Engineered Science Publisher remains neutral with regard to jurisdictional claims in published maps and institutional affiliations. 